\title{
COMUNICAÇÃOCIENTÍFICA
}

\section{ATIVIDADE DA REDUTASE DO NITRATO E FLUORESCÊNCIA DA CLOROFILA $a$ EM MAMOEIRO ${ }^{1}$}

\author{
RENATA VENTURIM FONTES², MIRELLA PUPO SANTOS ${ }^{3}$, ANTELMO RALPH FALQUETO $^{4}$, DIOLINA MOURA SILVA $^{5}$
}

RESUMO - O objetivo do presente trabalho foi correlacionar a atividade da redutase do nitrato e a eficiência fotoquímica máxima do fotossistema II (FSII), expressa pela razão $\mathrm{F}_{\mathrm{V}} / \mathrm{F}_{\mathrm{M}}\left(\mathrm{F}_{\mathrm{V}}=\right.$ fluorescência variável e $\mathrm{F}_{\mathrm{M}}$ = fluorescência máxima), em mamoeiro (Carica papaya L.) cv. Tainung 01 e Sunrise Solo 72/12 em condições de campo. O potencial fotoquímico do FSII foi medido in situ em folhas adaptadas ao escuro. Depois, nas mesmas folhas, foi medida a atividade da enzima. Não houve diferença significativa entre a eficiência fotoquímica máxima do FSII entre as cultivares Tainung 01 e Sunrise Solo 72/12, porém a atividade da redutase do nitrato foi notoriamente maior na primeira. A atividade da redutase do nitrato foi altamente correlacionada à eficiência fotoquímica máxima do FS II tanto na cv. Tainung 01 (coeficiente de correlação $r=0,740$ e coeficiente de determinação ${ }^{2}=0,706$ ) quanto na Sunrise Solo $72 / 12$ (coeficiente de correlação $r=0,960$ e coeficiente de determinação $r^{2}=0,945$ ). Esses resultados sugerem que há uma correlação entre a fluorescência da clorofila $a$ e a atividade da redutase do nitrato nessas plantas.

Termos para indexação: Carica papaya L., fluorescência da clorofila $a$, metabolismo do nitrogênio.

\section{NITRATE REDUCTASE ACTIVITY AND CHLOROPHYLL $a$ FLUORESCENCE IN PAPAYA}

ABSTRACT - The objective of the present work was to connect the nitrate reductase activity and the photochemical efficiency of the photosystem II (PSII), measured as $\mathrm{F}_{\mathrm{v}} / \mathrm{F}_{\mathrm{M}}$, in papaya (Carica papaya L.) cv. Tainung 01 and Sunrise Solo $72 / 12$ in field conditions. The photochemical potential of PSII was measured in situ on attached leaves that had been dark adapted, prior to the fluorescence measurement. After, in same leaves, the enzyme activity was measured. There was not significant difference among the photochemical efficiency of PSII between cv. Tainung 01 and Sunrise Solo 72/12, even so, the activity of the enzyme was markedly higher in cv. Tainung 01 than in cv. Sunrise Solo 72/12. The nitrate redutase activity was highly correlated with the photochemical efficiency of the PSII in both cv. Tainung 01 (coefficient of correlation $r=0,740$ and coefficient of determination $r^{2}=0,706$ ) and Sunrise Solo 72/12 (coefficient of correlation $r=0,960$ and coefficient of determination $r^{2}=0,945$ ). These results suggest that there is a correlation between chlorophyll $a$ fluorescence and nitrate reductase activity in these plants.

Index terms: Carica papaya L., chlorophyll a fluorescence, nitrogen metabolism.

O nitrato $\left(\mathrm{NO}_{3}^{-}\right)$é a principal forma nitrogenada absorvida pelas plantas. Entretanto, para que esse íon seja incorporado a compostos orgânicos no sistema radicular e na parte aérea, deve ser reduzido a amônio $\left(\mathrm{NH}^{4+}\right)$ (Netto, 2005). As reações de redução do $\mathrm{NO}_{3}^{-}$são realizadas por duas enzimas: a redutase do nitrato (RN, EC 1.6.6.1) e a redutase do nitrito (Viégas \& Silveira, 2002). A redutase do nitrato (RN) é considerada enzima-chave no processo de absorção do nitrogênio, pois catalisa o primeiro passo na via de redução do nitrato. De acordo com Tischner (2000), a RN é encontrada normalmente no citosol, porém há evidências de que também esteja presente na superfície externa da membrana plasmática. Segundo esse mesmo autor, sua atividade é influenciada por fatores como luz, teor de nitrato, ATP e NADPH, sendo estes dois últimos produzidos durante o processo fotossintético.
A fotossíntese ocupa uma posição central no metabolismo, fornecendo uma ligação entre processos internos da planta e o ambiente externo. O uso de parâmetros da fluorescência das clorofilas tem sido difundido, principalmente no estudo da capacidade fotossintética das plantas, por ser um método não-destrutivo que permite a análise qualitativa e quantitativa da absorção e aproveitamento da energia luminosa (eficiência fotoquímica do fotossistema II $-\mathrm{F}_{\mathrm{V}} / \mathrm{F}_{\mathrm{M}}$ ) pelo aparelho fotossintético. Essa técnica tem permitido um aumento no conhecimento dos processos fotoquímicos e não-fotoquímicos que ocorrem na membrana dos tilacóides, além de possibilitar o estudo de características relacionadas à capacidade de absorção e transferência da energia luminosa na cadeia de transporte de elétrons (Krause \& Weis, 1991).

${ }^{1}$ (Trabalho 063-07). Recebido em; 16-03-2007. Aceito para publicação em : 30-11-2007. Parte da Dissertação de Mestrado do primeiro autor. Apoio financeiro: CAPES, Banco do Nordeste e Brapex.

${ }^{2}$ Bióloga, MSc. em Biologia Vegetal, PPGBV/UFES, Doutoranda em Produção Vegetal, UENF, rvfontes@yahoo.com.br

${ }^{3}$ Bióloga, MSc em Biologia Vegetal, PPGBV/UFES, Doutoranda em Genética e Melhoramento de Plantas, UENF, mirellapupo@yahoo.com.br

${ }^{4}$ Biólogo, MSc. em Biologia Vegetal, PPGBV/UFES, Doutorando em Fisiologia Vegetal, UFPel, antelmofalqueto@yahoo.com.br

${ }_{5}^{5}$ Prof. Associado, DSc. Em Fisiologia Vegetal, Programa de pós-Graduação em Biologia Vegetal, Universidade Federal do Espírito Santo, Av. Fernando Ferrari, 514 - Goiabeiras - Vitória - ES. CEP 29075910, biovegetal@terra.com.br. 
De acordo com Carelli et al. (1996), a capacidade fotossintética das plantas é dependente do suprimento de nitrogênio. Uma considerável fração desse elemento encontrase nas folhas, alocado nas proteínas envolvidas no processo fotossintético. Em adição, a fotossíntese depende de vários compostos nitrogenados, como enzimas e pigmentos fotossintéticos, para a produção dos compostos de carbono que compõem a parte aérea. Por essa razão, a capacidade fotossintética das plantas e o metabolismo do nitrogênio estão diretamente interligados. Apesar da importância do nitrogênio para a cultura do mamoeiro, poucos são os estudos que correlacionam a atividade da $\mathrm{RN}$ à eficiência fotoquímica do fotossistema II. O objetivo deste estudo foi estabelecer uma relação entre a atividade da $\mathrm{RN}$ e a eficiência fotoquímica do FS $\mathrm{II}\left(\mathrm{F}_{\mathrm{V}} / \mathrm{F}_{\mathrm{M}}\right)$ em plantas de mamoeiro (Carica papaya L.) cvs. Tainung 01 e Sunrise Solo 72/12 em condições de campo. As plantas foram avaliadas em uma lavoura comercial (Frutas Herzok), no Município de Aracruz - ES (Latitude 1949'13 sul, Longitude $40^{\circ} 16^{\prime} 24$ oeste e Altitude de $60 \mathrm{~m}$ ) (IBGE, 2005). A cultura foi conduzida no campo sob irrigação e adubações de acordo com as recomendações para a cultura. As análises foram feitas durante os meses de setembro a dezembro do ano de 2003. A atividade da $\mathrm{RN}$ foi determinada em folhas jovens completamente expandidas e fisiologicamente maduras, cuja axila continha uma primeira flor aberta, após 18 meses de crescimento em campo. Utilizou-se do método in vivo, descrito por Jaworski (1971). Este método baseiase no princípio de que a concentração de nitrito $\left(\mathrm{NO}_{2}^{-}\right)$liberada por fragmentos de tecidos foliares em uma solução tampão, na presença de um agente permanente (propanol) e do substrato $\left(\mathrm{NO}_{3}^{-}\right)$, reflete a atividade potencial da $\mathrm{RN}$ in situ. A atividade da enzima é estimada pela quantidade de $\mathrm{NO}_{2}{ }^{-}$liberada na solução de incubação, medida em espectrofotômetro, a $540 \mathrm{~nm}$, e expressa em $\mu$ moles de $\mathrm{NO}_{2}^{-} \mathrm{h}^{-1} \mathrm{~g}^{-1}$ de matéria fresca. A emissão da fluorescência da clorofila foi determinada nas mesmas folhas utilizadas para a determinação da atividade da RN. A fluorescência da clorofila foi medida após 30 minutos de adaptação das folhas ao escuro, utilizando-se de um fluorômetro portátil Handy PEA (Plant Efficiency Analyzer, Hansatech Instruments Ltd., Norkfolk, $\mathrm{UK})$, o qual determina as características da fluorescência rápida da clorofila: fluorescência inicial $\left(\mathrm{F}_{0}\right)$, fluorescência máxima $\left(\mathrm{F}_{\mathrm{M}}\right)$, fluorescência variável $\left(\mathrm{F}_{\mathrm{v}}\right)$ e eficiência fotoquímica do FS II $\left(\mathrm{F}_{\mathrm{v}} /\right.$ $\mathrm{F}_{\mathrm{M}}$ ). $\mathrm{O}$ experimento foi conduzido em delineamento inteiramente casualizado, com 10 repetições. Os dados obtidos foram submetidos à análise de variância (Teste $\mathrm{F}$ ), e a interação entre a atividade da $\mathrm{RN}$ e a eficiência fotoquímica do FS II, para as cultivares Tainung 01 e Sunrise Solo 72/12, foi obtida por meio de análises de regressão polinomial, conforme Pimentel-Gomes (1990).

As variáveis analisadas neste estudo diferiram significativamente entre as cultivares testadas. A cv. Tainung 01 apresentou atividade da RN superior à cv. Sunrise Solo 72/12 (Figura 1). De acordo com Campbell (1999), a absorção do nitrogênio, bem como a atividade da enzima $\mathrm{RN}$, é influenciada pelas características genéticas da cultivar. Segundo Redinbaugh \& Campbell (1991), a RN é uma enzima induzida, caracteristicamente, pelo seu substrato. Portanto, sua atividade reflete a concentração de nitrato $\left(\mathrm{NO}_{3}^{-}\right)$e de nitrito $\left(\mathrm{NO}_{2}^{-}\right)$no solo e nos tecidos vegetais, respectivamente. Assim, os resultados observados neste estudo sugerem que a cultivar Tainung 01 apresenta mecanismos de absorção e de metabolismo do nitrogênio mais eficientes que a cultivar Sunrise Solo. A eficiência fotoquímica do FS II, representada pela relação $F_{v} / F_{M}$, não diferiu estatisticamente entre as cultivares (Figura 2). Essa relação indica a produção quântica fotoquímica máxima do FS II, podendo ser definida também como a produção máxima da fotoquímica primária. A relação entre eficiência fotoquímica inicial e máxima é um bom indicativo da capacidade de captura da energia luminosa dos centros de reação do FS II abertos, quando as folhas estão adaptadas ao escuro e os aceptores de elétrons do FS II estão totalmente oxidados (Van Kooten \& Snel, 1990). De acordo com Ribeiro et al. (2004), os valores de $\mathrm{F}_{\mathrm{V}} / \mathrm{F}_{\mathrm{M}}$ podem variar de 0,750 a 0,850 . Entretanto, os valores médios obtidos para as cultivares Tainung 01 e Sunrise Solo 72/12 foram de 0,699 e 0,692, respectivamente (Figura 2). Esses resultados contrariam aqueles obtidos por Marler \& Mickelbart (1998) quando, trabalhando com plantas do mamoeiro 'Red Lady', verificaram que não houve alterações na eficiência fotoquímica máxima do fotossistema II $\left(\mathrm{F}_{\mathrm{v}} / \mathrm{F}_{\mathrm{M}}>0,75\right)$ em dias de céu claro, tal qual o deste estudo. Considerando que o período de amostragem, desse experimento, ocorreu durante os meses de setembro (período seco) até dezembro (período chuvoso) e que as taxas de pluviosidade e temperatura foram crescentes (dados não mostrados) a baixa eficiência fotoquímica obtida pode ter sido conseqüência dessas variações climáticas. Segundo Carelli et al. (1996), o metabolismo do nitrogênio e do carbono é interdependente, pois a energia necessária para a assimilação do nitrogênio deriva direta ou indiretamente da fotossíntese, ao passo que esta depende do suprimento de nitrogênio. Baseado nessa afirmativa, foi feita a relação entre a atividade da $\mathrm{RN}$ e a eficiência fotoquímica do FS II do mamoeiro cv. Tainung 01 e Sunrise Solo 72/12 (Figura 3). Observou-se, para as duas cultivares, tendência de aumento da atividade da enzima com o aumento dos valores de $F_{V} / F_{M}$, fato também observado por Netto (2005) em cafeeiro. Ao se correlacionar a atividade da $\mathrm{RN}$ e os valores de $\mathrm{F}_{\mathrm{v}} / \mathrm{F}_{\mathrm{M}}$, verificou-se, por meio dos coeficientes de correlação (r) obtidos, maior interdependência do metabolismo do nitrogênio e do carbono nas plantas da cv. Sunrise Solo 72/12 (Figuras 3A e 3B).

Os resultados obtidos mostraram que a atividade da RN foi maior nas plantas da cultivar Tainung 01, e acompanhou o aumento em Fv/Fm, nas duas cultivares estudadas; e nas plantas da cultivar Sunrise Solo 72/12, a atividade da redutase do nitrato parece ter maior interdependência do metabolismo do nitrogênio e do carbono. 


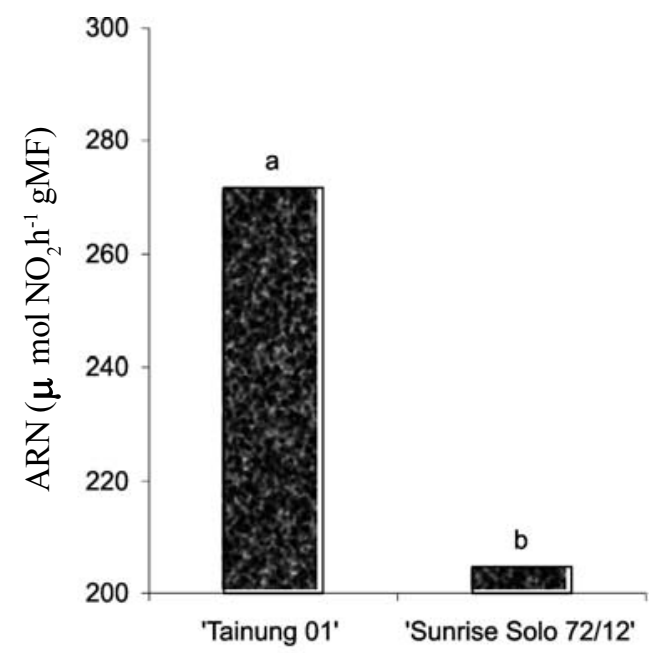

FIGURA 1 - Atividade da enzima redutase do nitrato (ARN) em folhas de cultivares de mamoeiro cv. Taiunug $01 \mathrm{e}$ Sunrise Solo 72/12.
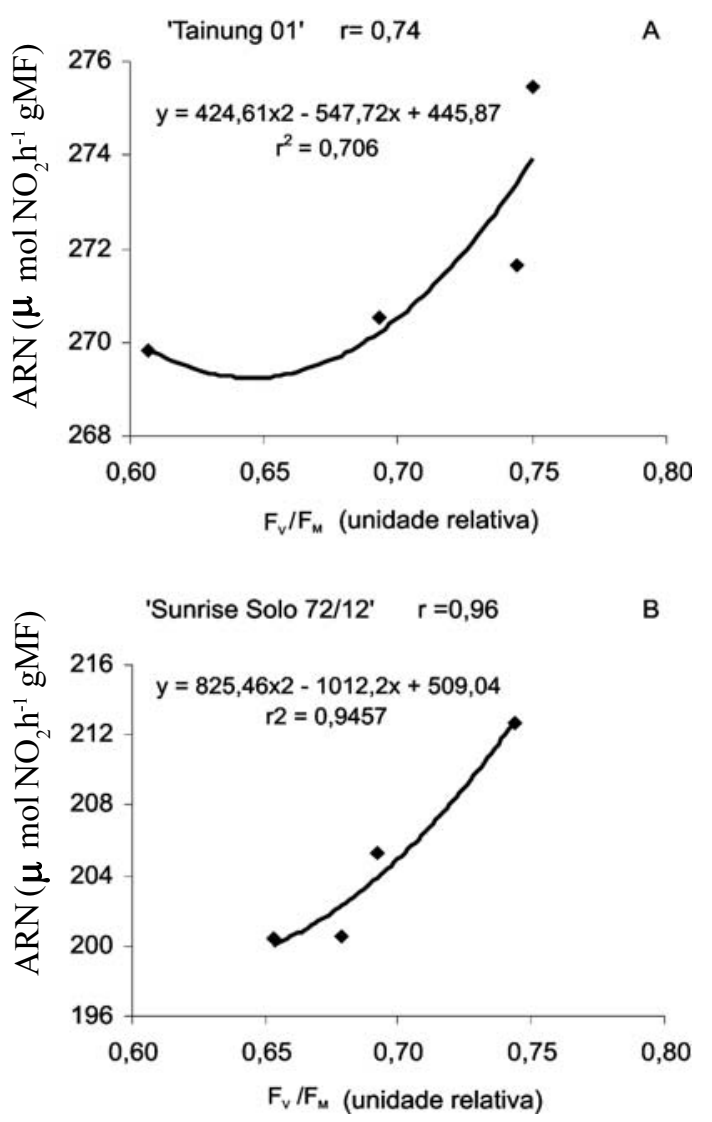

FIGURA 3 - Correlação entre a atividade da redutase do nitrato $(\mathrm{ARN})$ e a eficiência fotoquímica do fotossistema II $\left(\mathrm{F}_{\mathrm{v}} / \mathrm{F}_{\mathrm{M}}\right)$ em plantas de mamoeiro cultivar Tainung 01 (A) e Sunrise Solo 72/12 (B). $r=$ coeficiente de correlação; $r^{2}=$ coeficiente de determinação da análise de regressão.

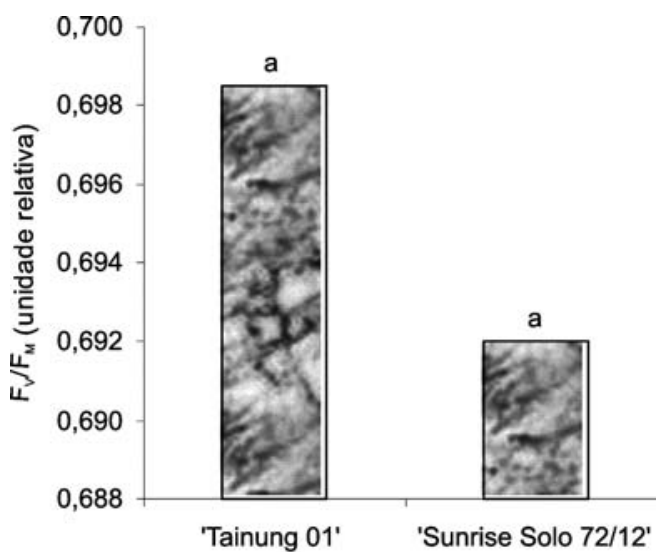

FIGURA 2 - Eficiência fotoquímica do fotossistema II $\left(\mathrm{F}_{\mathrm{v}} / \mathrm{F}_{\mathrm{M}}\right)$ obtida em folhas de cultivares de mamoeiro cv. Taiunug 01 e Sunrise Solo 72/12.

\section{REFERÊNCIAS}

CAMPBELL, W. H. Nitrate reductase structure, function and regulation: bridging te gap between biochemistry and physiology. Annual Review Plant Physiology and Plant Molecular Biology, Palo Alto, v.50, p.277-303, 1999.

CARELLI, M. L. C.; UNGARO, M. R. G.; FAHL, J. I. e NOVO, M. do C. S. S. Níveis de nitrogênio, metabolismo, crescimento e produção de girassol. Revista Brasileira de Fisiologia Vegetal, Brasília, v.8, n 2, p.123-130, 1996.

IBGE (Instituto Brasileiro de Geografia e Estatística). Disponível em <www.ibge.gov.br.>Acesso em: fev. 2005.

JAWORSKI, E. G. Nitrate reductase assay in intact plant tissues. Biochemical and Biophysical Research Communications, Orlando, v.43, n.6, p.1274-1279, 1971.

KRAUSE, G. H.; WEIS, E. Chlorophyll fluorescence and photosynthesis: The basics. Annual Review of Plant Physiology and Plant Molecular Biology, Palo Alto, v.42, p.313-349, 1991.

MACHADO FILHO, J. A.; CAMPOSTRINI, E.; YAMANISHI, O. K.; FAGUNDES, G. R.Variação sazonal das trocas gasosas em folhas de mamoeiro cultivado em condições de campo. Bragantia, Campinas, v.65, n.2, p.185-196, 2006.

MARLER, T.E.; MICKELBART, M. V. Drought, leaf gas exchange, and chlorophyll fluorescence of field-grown papaya. Journal of the American Society for Horticultural Science, Alexandria, v.123, p.714-718, 1998.

NETTO, J. F. A. Atividade das enzimas redutase do nitrato e glutamina sintetase em cafeeiro arábica. 2005. 60 f. Dissertação (Mestrado em Agronomia, Fitotecnia) - Escola Superior de Agricultura “Luiz de Queiroz", Universidade de São Paulo, São Paulo, 2005. 
PIMENTEL-GOMES, F. Curso de estatística experimental. 13.ed. Piracicaba: Nobel, 1990.467p.

REDINBAUGH, M. G.; CAMPBELL, W. H. Higher plant responses to environmetal nitrate. Physiologia Plantarum, Copenhagen, v.28, p.640-650, 1991 .

RIBEIRO, R. V.; DOS SANTOS, M. G.; SOUZA, G. M.; MACHADO, E. C.; DE OLIVEIRA, R. F.; ANGELOCCI, L. R.; PIMENTEL, C. Environmental effects on photosynthetic capacity of bean genotypes. Pesquisa Agropecuária Brasileira, Brasília, v.39, n.7, p.615-623, 2004.
TISCHNER, R. Nitrate uptake and reduction in higher and lower plants. Plant Cell and Environnment, Oxford, v.23, n.10, p.10051024,2000

VAN KOOTEN, O.; SNEL, J. F. H. The use of chlorophyll fluorescence nomenclature in plant stress physiology. Photosynthesis Research, Dordrecht, v.25, n.3, p.147-150, 1990.

VIÉGAS, R. A.; SILVEIRA, J. A. G. Activation of nitrate reductase of cashew leaf by exogenous nitrite. Brazilian Journal of Plant Physiology, São Paulo, v.14, n.1, p.39-44, 2002. 